\title{
Los neologismos no nos sirven únicamente para expresarnos y para denominar, nos sirven también para distinguirnos de los demás
}

\section{Neologisms not only help us express and define ourselves, but also to distinguish ourselves from others}

\section{María Teresa CABRÉ}

Departamento de Traducción y Ciencias del Lenguaje, Universidad Pompeu Fabra teresa.cabre@upf.edu

\section{INTRODUCCIÓN}

En esta entrevista, realizada en el marco del III Congreso Internacional de Neología en las Lenguas Románicas (CINEO) celebrado en Salamanca en 2015, la Catedrática de Lingüística y Terminología María Teresa Cabré habla de los límites y las posibilidades de la teoría, destaca el papel de los hablantes como vigilantes de la lengua y reivindica el multilingüismo.

Palabras clave: neologismos; terminología; lingüística. 


\section{ENTREVISTA}

Fecha: 11/4/2015

Mateo-Pierre Avit: $Y$ hoy tenemos el placer de entrevistar a una eminencia en el campo de la Terminología como es Teresa Cabré. Buenas tardes, Teresa.

Teresa Cabré: Hola, buenas tardes.

M: Vamos a plantearle, si le parece bien, una serie de cuestiones a raíz de su intervención en el CINEO, pero también desde un punto de vista más amplio, de lo que es tanto la terminología como la neología. Sara, ¿querías empezar?

Sara de Blas: Sí. Me gustaría hacer una pregunta acerca de la conferencia que acaba de dar hace unos minutos. Hablábamos de principios, parámetros, criterios. Creo que son conceptos tal vez un poco vagos, no son sólidos, y usted plantea la creación de una teoría de la neología. ¿Cómo se puede llegar a plantear esta teoría de la neología? ¿Cómo se va a llegar a la teoría de la neología y el tiempo más o menos que esto va a llevar?

TC: Bueno, en realidad, no se trata de hacer una teoría de la neología, sino una teoría del neologismo, que son dos puntos de vista distintos. Porque el neologismo es un objeto de conocimiento observable y la neología en general no es observable, ${ }^{\circ}$ porque es tan amplia que tú te puedes perder. En principio lo que trató básicamente, y esto ya lo hice con la terminología, es centrarme en un objeto. ¿Cuál es el objeto núcleo central de la terminología? Los términos. ¿Cuál es el objeto central de la neología? Los neologismos. Pues bien, vamos a ver qué es un neologismo, cómo se comporta este neologismo. Para esto debemos saber, primero, qué es un neologismo y después, a continuación, decir cómo podemos observarlo y dónde. Cuando nos enfrentamos con una pregunta sobre qué es un neologismo, ¿con qué nos encontramos? Con que cualquier objeto de conocimiento es un objeto complejo, por tanto que tiene varias caras, tiene varias facetas. Por eso, yo le llamo el principio de poliedricidad. Todo objeto de conocimiento es poliédrico, de la misma manera que lo es cualquier objeto de la realidad. Porque si tú tomas, por ejemplo, una botella y la miras en posición horizontal o en posición vertical, tú ves cosas distintas y se trata del mismo objeto. Pues con el conocimiento pasa lo mismo. Según desde dónde lo mires, tú ves aspectos o características distintas. Por tanto, me encuentro ante un objeto, un neologismo, que es complejo y además, en el caso del neologismo, me encuentro con un objeto qué cambia, que es lábil. ¿Por qué? Lo que es neologismo un día puede dejar de serlo al cabo de un periodo, o lo que es neologismo para alguien puede no serlo para otra persona. Por ejemplo, tú puedes utilizar una palabra que es un localismo salmantino y para mí es un neologismo. Al tortazo lo llamáis, a la empanada típica de Salamanca...

María Teresa CABRÉ

Los neologismos no nos sirven únicamente para expresarnos y para denominar, nos sirven...
CLINA

vol. 7-1, June 2021, 95-102

elSSN: 2444-1961

Ediciones Universidad de Salamanca - CC BY-NC-ND 
TC: Hornazo. Yo oí hoy por primera vez esta palabra «hornazo». Para mí era un neologismo absoluto, en cambio para ti no lo era, porque lo conocías perfectamente. Una vez tú ya has delimitado cuál es tu objeto y te das cuenta de que es complejo, entonces tienes que describir su complejidad antes de pasar a otra cosa. Esta poliedricidad, esta complejidad, la resuelvo en términos de dimensiones y de perspectivas en el caso de los neologismos, que es lo mismo que hacíamos con los términos, dimensiones. Tú dices, ¿qué es un término? Un término es una unidad al mismo tiempo lingüística, cognitiva y social. ¿Puedo dar cuenta de este término con la misma profundidad desde todas las facetas al mismo tiempo? Es imposible. De la misma manera que cuando observas un objeto de la realidad no puedes verlo desde todos sus ángulos; es el problema que se planteó el cubismo, ¿vale? Pues, entonces, tú trazas las dimensiones de este objeto y luego, a continuación, es cuando viene, ¿y dónde lo veo yo a este objeto? Y es el caso de un punto de partida de la faceta lingüística y yo me lo encuentro en el texto, me lo encuentro en un discurso. Son los principios básicos.

M: Y ahora me gustaría plantear una cuestión que tal vez le parezca trivial, pero desde mi faceta de lego me veo obligado a plantear. ¿Cuándo un neologismo deja de serlo? Es decir, en cuestiones de análisis, ¿se hace a partir de repeticiones, de periodos de tiempo? ¿Cómo se plantea este análisis?

TC: Vamos a ver. Un neologismo siempre es una unidad que aparece en un momento determinado en el tiempo y puede dejar de ser neologismo a lo largo del tiempo. Pero es un fenómeno sincrónico, por tanto, tú en principio detectas un neologismo porque es una nueva aparición, ya sea porque aparece una palabra nueva, o ya sea porque a una palabra que tuya utilizabas le cambias el sentido, la utilizas con otro sentido. Entonces, aparece un neologismo. ¿Cuándo deja de ser neologismo? Pues aquí hay varias teorías. Una es la percepción, cuando yo dejo de percibir que una unidad es nueva, no es neologismo. Pero fijate, que si tomamos la percepción, cuando nosotros hacemos neologismos con las reglas de nuestra propia lengua, como pasan desapercibidos incluso para nosotros, más para un receptor, entonces habría unidades que son neológicas y que no se reconocerían nunca como neológicas. Por tanto, tiene que haber algún criterio que te diga "deja de ser neológica en el momento» y es por esto que normalmente en los círculos de trabajo sistemático se suele partir del criterio del corpus de exclusión. Es decir, «será neologismo lo que yo no encuentre en los diccionarios». Tendré muchas palabras que nos dan los diccionarios porque no tienen que estar y, en cambio, no son neologismos. Tendré en el diccionario muchas palabras que se usan desde hace mucho tiempo, por tanto, desde el punto de vista de mi percepción, no son neologismos. Esto es lo que ha llevado a decir «pero el corpus de exclusión tiene que ser matizado». No son sólo los diccionarios, sino que tienes que tener

María Teresa CABRÉ

Los neologismos no nos sirven únicamente para expresarnos y para denominar, nos sirven...
CLINA

vol. 7-1, June 2021, 95-102

elSSN: 2444-1961

Ediciones Universidad de Salamanca - CC BY-NC-ND 
un corpus formado por varios textos de exclusión. El último es Internet. Si una unidad no está en Internet, es obvio que es un neologismo, por ejemplo.

S: A mí me suena interesante el papel del usuario, de los hablantes. Ha hecho mucho hincapié en su conferencia en esa parte, en esa perspectiva sociopsicológica. ¿Hasta qué punto es el usuario el protagonista de todo este proceso, los hablantes?

TC: Los hablantes siempre son protagonistas de la lengua, siempre. Porque una lengua es una entelequia que, si no hubiera hablantes que la externalizaran, que la materializaran, no tendríamos lengua, por decirlo de alguna manera. $Y$ yo sobre todo en lo que he hecho hincapié es en que nuestras palabras, nuestro lenguaje, no tiene únicamente una dimensión gramatical o lingüística, sino que tiene otras dimensiones. La primera y fundamental es la dimensión social. Hacemos servir al lenguaje para comunicarnos, hacemos servir al lenguaje para identificarnos, hablamos de una lengua, hacemos servir el lenguaje para jerarquizarnos, hablamos de lengua culta, de lengua vulgar, etc. El que domina el lenguaje de una profesión es reconocido como profesional. Tú puedes encontrarte a una persona que sepa mucho de algo, pero si no habla con las reglas lingüísticas propias del ámbito no se le reconoce como profesional, porque va aparejado la lengua y el conocimiento sobre esto. $Y$ lo que he intentado hacer yo es distinguir qué es aquello que se explica por razones del propio lenguaje, de su gramática, y qué se explica por cuestiones de la sociedad o de la psique, de la mente, por ejemplo. Yo puedo utilizar un neologismo porque intento denominar algo que me ha llegado nuevo, y esto está plenamente justificado. Pero muchas veces, ¿por qué utilizo un neologismo? ¿O por qué unas personas ante la denominación de un objeto utilizan un neologismo formado con las reglas de la lengua y otros utilizan sistemáticamente el préstamo? Pues porque tienen dos actitudes distintas ante la lengua. Si observas, esto es un fenómeno psicosocial. Por tanto, los neologismos no nos sirven únicamente para expresarnos y para denominar, sino que nos sirven también para distinguirnos de los demás, para mostrarnos, para separarnos de un grupo determinado, para alejarnos de estos usos, etc. Nos sirven para muchas cosas. Estos son mecanismos que no forman parte propiamente de la lingüística. La lingüística, la gramática y la pragmática sólo pueden recoger o dar cuenta del conocimiento que tenemos sobre el lenguaje y de cómo lo utilizamos, pero de nada más. Por tanto, qué es lo que nos mueve a nosotros a distinguirnos del otro no es una cuestión lingüística, es una cuestión, en todo caso, de teoría del comportamiento de lo que tú quieras.

S: $Y$ en este en este congreso también se han presentado muchos proyectos que quieren llegar al usuario, llegar a los hablantes. Por ejemplo, lo que presentaba ayer la Neolosfera, un proyecto muy interesante. ¿Cree usted que deberían favorecerse todo este tipo de proyectos para llegar a los hablantes con las redes sociales? El TERMCAT, por ejemplo, también tiene su cuenta de Twitter, tiene Facebook. Publican

María Teresa CABRÉ Los neologismos no nos sirven únicamente para expresarnos y para denominar, nos sirven...
CLINA

vol. 7-1, June 2021, 95-102

elSSN: 2444-1961

Ediciones Universidad de Salamanca - CC BY-NC-ND 
semanalmente también, como una cuestión de periodicidad, para que el usuario sepa que cada semana se va a publicar algo relacionado con esto. ¿Cree que esto es importante?

TC: Creo que es importante como mecanismos de llamar la atención y de adhesión a algo. Es decir, ¿la neología en sí es importante? Pues mira, qué quieres que te diga. Lo que es importante es comer cada día. No necesitas tener una noción o conocimiento sobre la neología, de las nuevas palabras. Pues no, tú vas haciendo tu vida diaria y esto no es necesario. Pero en cambio, si tú presentas las cosas a través de, por ejemplo, la Neolosfera, o de los comentarios que hace el TERMCAT a través de lo que es las nuevas redes sociales, por tanto llegas a muchísima más gente, pero de una forma atractiva creas una especie de adhesión a este tipo de conocimiento y esto es lo que es importante. Para crear adhesión hacia un conocimiento, hacia un organismo, se utilizan mecanismos del tipo de los que tú hablas.

S: También hemos visto que en el congreso, en CINEO, participan representantes de diferentes lenguas: catalán, gallego, portugués, español... ¿Hasta qué punto las diferencias entre las lenguas hacen que se tambalee, tal vez, que sea más débil esa teoría que usted propone de los de los neologismos? ¿La diferencia es una ventaja o un inconveniente?

TC: No es ni una ventaja ni un inconveniente. Es decir, cuando tú haces una teoría, la teoría debe dar cuenta de los datos, sean en la lengua que sean. Si tú te mueves en el terreno epistemológico, tus principios tienen que servir para cualquier lengua, si no, no es una teoría. ¿Entiendes? Por tanto, no tiene nada que ver en este sentido. Pero en cambio, la diversidad lingüística, por ejemplo, en neología, te sirve para otras cosas que son muy interesantes. La constatación es que actualmente estamos absolutamente globalizados, más de lo que nosotros pensamos. Ayer, me parece, o anteayer, asistí a una comunicación en la que se hablaba de los verbos neológicos formados por conversión. La conversión es una regla que tenemos en nuestra propia lengua. Es decir, por ejemplo: de beso, besar, de abrazo, abrazar. Por tanto, nosotros formamos un verbo a partir de un nombre y es algo que asimilamos como las palabras regulares en nuestro sistema. Se presentaron verbos neológicos, por ejemplo, de Google, googlear, y tú dices, ¿de dónde viene esto? No es el ejemplo de Google, he tomado un mal ejemplo, porque no tenía que ser «-ear», sino uno directo. De click, clicar, por ejemplo. ¿Qué procedimiento está utilizando? El de la conversión, ¿pero realmente ha formado esta palabra? No, lo que ha interiorizado es una regla del inglés que es mucho más frecuente que en español, que es la regla de la conversión de tomar click, como nombre y como verbo. Entonces, tenemos tendencia a adoptar mecanismos. Sin darnos cuenta, hemos sido colonizados no únicamente por palabras, sino también por mecanismos gramaticales que no tienen la misma frecuencia en nuestra lengua. Esto lo demostró una chica que hizo una tesis con Joaquín García Palacios. Trabajaba sobre un ámbito

María Teresa CABRÉ

Los neologismos no nos sirven únicamente para expresarnos y para denominar, nos sirven...
CLINA

vol. 7-1, June 2021, 95-102

elSSN: 2444-1961

Ediciones Universidad de Salamanca - CC BY-NC-ND 
de especialidad y mostró cómo la gran mayoría de palabras de este ámbito, que eran palabras absolutamente románicas, en realidad no eran románticas, las tomábamos del inglés. Por tanto, a veces vemos una palabra, la vemos nueva y bien formada por las reglas del español y pensamos que esto ha formado parte de nuestra actividad léxica, por tanto, nosotros tenemos adhesión a nuestra lengua. Pero no es verdad, es un proceso que hemos tomado de fuera.

M: Y ahora volviendo digamos esta diversidad de lenguas románicas en las que se centra el CINEO, como sabrán nuestros oyentes usted es especialista en catalán pero también, si no me equivoco, trabaja con el castellano. ¿Qué diferencias hay en el enfoque a la hora de investigar estas dos lenguas?

TC: Desde el punto de vista del enfoque lingüístico, ninguno. Es lo que te decía antes, una teoría tiene que servir para todo, sea la lengua que sea. Por tanto, todo lo que es la metodología de descripción, los tipos, etc. tiene que servir para todas las lenguas románicas, porque si no está mal formulada. Lo que sí que nosotros notamos es que las condiciones demográficas y sociológicas o sociopolíticas del catalán y el castellano tienen repercusiones incluso en las actitudes de los hablantes con relación a la neología. Cuando nosotros recogemos los datos por ejemplo observamos que el hablante español es mucho más permeable al préstamo porque lo ve como una cosa normal, no tiene ninguna prevención al préstamo, a no ser que sea un militante de la lengua muy purista. El hablante de español es descuidado. Pero, ¿por qué razón? Porque sabe que su lengua se está hablando por tantos millones de hablantes que la lengua está asegurada. Cuando tú formas parte de una lengua minoritaria o minorizada, en este caso el catalán, que es las dos cosas al mismo tiempo, tú sabes que en la medida que tu lengua se abra la interferencia sin ningún control, como hay tan pocos hablantes, llegará un momento en el que esta lengua estará colonizada por otra. Esto en sociolingüística se describe como la sustitución lingüística, una etapa de diglosia que pasa a la sustitución lingüística. Por lo tanto, el hablante del catalán está mucho más vigilante, tiene una actitud mucho más mucho más vigilante ante los préstamos. Porque un préstamo causa más daño a una lengua que no está estabilizada desde el punto de vista político y desde el punto de vista demográfico, como en el caso del español. Es una actitud de vigilia, es una actitud.

S: Entonces sí que es posible esa actitud, esa acción conjunta de todas las lenguas románicas contra el idioma de la globalización que es el inglés. ¿Es posible?

TC: Sí, pero planteado en otros términos. No se trata de contra. Fíjate bien, yo pienso que una buena política del multilingüismo tiene que pasar por tratar el inglés en el conjunto del resto de lenguas, no contra el inglés. El inglés es un idioma que sirve para determinadas funciones en el ámbito internacional. El problema es cuando estas funciones, que son lógicamente necesarias, tú intentas adoptar esta lengua para otras

María Teresa CABRÉ

Los neologismos no nos sirven únicamente para expresarnos y para denominar, nos sirven...
CLINA

vol. 7-1, June 2021, 95-102

elSSN: 2444-1961

Ediciones Universidad de Salamanca - CC BY-NC-ND 
funciones que no están necesariamente justificado que se utilice. Por ejemplo, a mí me parece ridículo que se hagan coloquios nacionales, por ejemplo, y los hagan en inglés. Me parece absolutamente ridículo. Tú dices «pero bueno, el inglés es una lengua vehicular». Sí, pero si nos vamos acostumbrando a que en estas situaciones que son de prestigio siempre vamos utilizando el inglés porque es lengua vehicular internacionalmente, ¿qué pasa? Que nuestra lengua propia reculará y ya no se tratará en estos temas, y con esto vamos perdiendo dominios de uso de la lengua. Por lo tanto, no es contra el inglés, sino que cada lengua ha de tener en una sociedad el papel que le corresponde. Esto es lo que intentaba decir yo, que no me salía la palabra, el principio de sustituibilidad. ¿Qué significa? Tú tienes que utilizar la lengua tuya, propia, siempre que sea posible. Cuando no sea posible, por ejemplo, en un máster internacional tú tienes estudiantes de fuera. Es evidente que tú no puedes recibirlos en la lengua propia del país si lo has anunciado como un máster internacional. Pero, por ejemplo, en el caso catalán que son temas que yo he tocado porque he dirigido el servicio lingüístico de la Universidad de Barcelona, si tú a un estudiante que viene de fuera le dices «tú no te preocupes, vamos a dar las clases en castellano o en inglés, no pasa nada. Pero dentro de tres meses, tú tienes que tener la capacidad de entender en otras lenguas». Y le ofreces los mecanismos para conseguirlo, lo estás enriqueciendo. Es decir, en lugar de amputarle una mano, al contrario le estás dando un guante para que tenga más recursos. Entonces yo pienso que siempre hay que plantear el término del multilingüismo, de la adquisición de nuevas lenguas, como un rasgo positivo. Por eso no me gusta la dicotomía de los contras. Y creo que en este momento el Consejo de Europa, en el Consejo Europeo de las Lenguas, se está trabajando básicamente sobre esta aproximación. Yo tampoco soy especialista en este tema.

M: Bueno, pues parece ser que hemos llegado a nuestro fin de esta interesantísima entrevista. Así que, agradecemos muchísimo a la señora Cabré que haya accedido a esta entrevista. La hemos entrevistado a raíz de bueno pues su ponencia, que fue de clausura, en el CINEO titulada «Principios y parámetros una teoría sobre los neologismos». Así que, muchísimas gracias de nuevo, Teresa.

TC: Al contrario, ha sido un placer.

Entrevista: «Don de Lenguas, Matero-Pierre Avit, Sara de Blas»

Transcripción: Beatriz Guerrero García

Enlace: https://programadondelenguas.blogspot.com/2015/11/font-definitions-font-face-font.html Duración: 21:35:00

María Teresa CABRÉ

Los neologismos no nos sirven únicamente para expresarnos y para denominar, nos sirven...
CLINA

vol. 7-1, June 2021, 95-102

elSSN: 2444-1961

Ediciones Universidad de Salamanca - CC BY-NC-ND 


\section{NOTA BIOGRÁFICA}
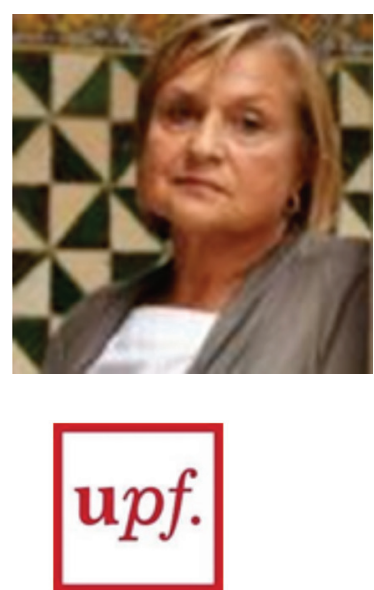

María Teresa Cabré es Catedrática de Lingüística y Terminología de la Universidad Pompeu Fabra. Fue directora del TERMCAT desde 1982 a 1988 y es miembro fundadora de la Red Iberoamericana de Terminología (Riterm), de la Red Panlantina de Terminología (Realiter) y del grupo de léxico de la European Linguistic Research Association, así como doctora honoris causa por la Universidad de Ginebra (2018). Desde 2021 preside el Institut d'Estudis catalanes.

\section{María Teresa Cabré: https://orcid.org/}

\section{BIBLIOGRAFÍA}

Cabré, M. T. 1999. «Hacia una teoría comunicativa de la terminología: Aspectos metodológicos». Revista Argentina de Lingüística.

Cabré, M. T. 1999. La terminología: Representación y comunicación: Elementos para una teoría de base comunicativa y otros artículos. Barcelona: Universitat Pompeu Fabra. Institut Universitari de Lingüística Aplicada.

Cabré, M. T. 1993. La terminología. Teoría, metodología, aplicaciones. Editorial Antártida / Empúries, Barcelona. 